\title{
Induction of Apoptosis Pathways in Several Cell Lines following Exposure to the Marine Algal Toxin Azaspiracid
}

\author{
Michael J. Twiner, ${ }^{*}, \ddagger$ Joshua C. Hanagriff, ${ }^{\ddagger}$ Suzanne Butler, ${ }^{\ddagger}$ Ahmed K. Madhkoor, \\ and Gregory J. Doucette \\ ${ }^{\dagger}$ Department of Natural Sciences, University of Michigan-Dearborn, Dearborn, Michigan 48128, United States \\ ${ }^{\ddagger}$ Marine Biotoxins Program, National Oceanic and Atmospheric Administration/National Ocean Service, Charleston, South Carolina \\ 29412, United States \\ ${ }^{\S}$ Grice Marine Laboratory, College of Charleston, Charleston, South Carolina 29424, United States
}

ABSTRACT: Azaspiracids (AZAs) are polyether marine dinoflagellate toxins that accumulate in shellfish and represent an emerging human health risk. Although there have been no deaths associated with the AZA toxins, humans exposed to AZAs experience severe gastrointestinal symptoms. This toxin class has been shown to be highly cytotoxic, a teratogen to developing fish, and a possible carcinogen in mice. Just recently, the AZAs have been shown to be potassium channel inhibitors. This report employed multiple human cell lines [Jurkat T lymphocytes, Caco-2 intestinal cells, and BE(2)-M17 neuroblastoma cells] in characterizing cytotoxicity and pathways of apoptosis. Cytotoxicity experiments were consistent with published literature that has shown that AZA1 is cytotoxic in both a concentration- and timedependent manner to each cell type tested, with mean $\mathrm{EC}_{50}$ values ranging between 1.1 and $7.4 \mathrm{nM}$. Despite the absence of morphological indices indicating apoptosis, caspase-3/7 activity was higher in all cell types treated with AZA1. Furthermore, in T

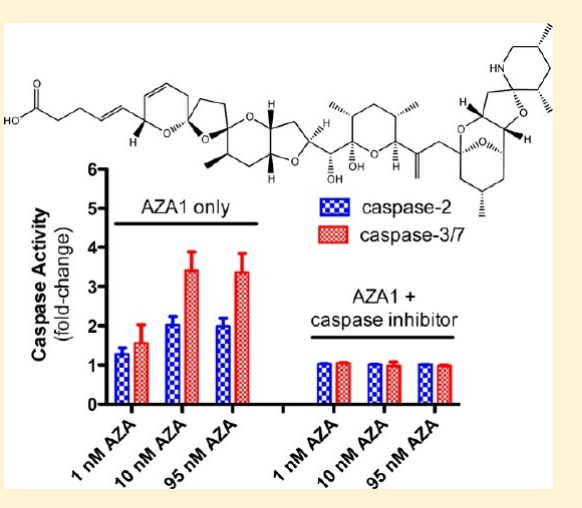
lymphocytes, the most sensitive cell type, the activities of initiator caspase-2 and caspase-10 and concentrations of intracellular cytochrome $c$ were elevated. DNA fragmentation was also observed for T lymphocytes exposed to AZA1-AZA3. Collectively, our data confirm that AZA1 was highly cytotoxic to multiple cell types and that cells exposed to AZA1 underwent atypical apoptosis, possibly in conjunction with necrotic cytotoxicity.

\section{INTRODUCTION}

Azaspiracid (AZA) was identified following an outbreak of shellfish poisoning in The Netherlands in $1995 .{ }^{1}$ Examination of the source site, Killary Harbour, Ireland, and suspected contaminated mussels revealed a previously unknown toxin initially called Killary Toxin-3 (KT-3). The compound was later named azaspiracid because of its unique structure: a cyclic amine, or aza group, with a trispiro assembly and carboxylic acid group. ${ }^{2}$ Outbreaks of human illness or detection of the toxin has since been reported throughout Western Europe ${ }^{3}$ and Morocco $^{4}$ as well as Canada (M. Quilliam, personal communication) and the United States, ${ }^{5}$ suggesting that this emerging algal toxin is a widespread public health concern. Symptoms resulting from human consumption of AZAcontaminated shellfish include nausea, diarrhea, vomiting, and stomach cramps, although no fatalities have occurred. ${ }^{\prime}$ The potential for negative ecological disturbances has also been suggested on the basis of studies demonstrating adverse effects of AZA on embryonic fish development. ${ }^{7}$ Over the past decade, extensive progress also has been made on elucidating the chemical structure of AZA and its derivatives. ${ }^{8}$ To date, more than 20 naturally occurring analogues of the toxin have been described, ${ }^{9,10}$ three of which are commonly detected in toxigenic Azadinium, a recently discovered dinoflagellate source of AZAs. ${ }^{11,12}$
Results from in vivo studies using rodent models have shown AZA1 to be highly potent and capable of inducing severe degradation of the intestinal tract and ultimately causing the death of the animals. ${ }^{13-15}$ In developing fish embryos, AZA1 caused significant growth retardation and abortion. ${ }^{7}$ In vitro, the AZAs have been reported to cause a range of cellular and molecular toxic effects. AZAs are potent cytotoxins ${ }^{16-18}$ that elevate caspase activity, ${ }^{19,20}$ induce irreversible cytoskeletal rearrangements, ${ }^{16,21,22}$ increase cellular concentrations of $\mathrm{Ca}^{2+}$ and cAMP, ${ }^{23,24}$ deplete cellular ATP,${ }^{25}$ inhibit neuronal ion flux and bioelectrical activity, ${ }^{19,26}$ inhibit membrane protein endocytosis $^{27}$ and cell-cell adhesion, ${ }^{28}$ and stimulate cholesterol biosynthesis. ${ }^{29}$ Although additional targets may be identified, the AZA toxins have just recently been identified as open state blockers of human ether-a-go-go-related gene (hERG) potassium channels. ${ }^{30}$

Apoptosis or programmed cell death, in contrast to necrosis, is an important process used to eliminate dangerous or superfluous cells ${ }^{31}$ and is thus significant in development and tissue maintenance and stability. Apoptosis is defined by characteristic pyknosis (i.e., chromatin condensation), degradation of DNA, cell shrinkage, and fragmentation of the

Received: April 20, 2012

Published: June 22, 2012 
nucleus $^{32}$ and is commonly identified by two main indicators within the cell: the presence of activated caspases and DNA fragmentation within the nucleus. Caspases are cysteinedependent aspartate-specific proteases that are essential players in the apoptotic pathway. ${ }^{33}$

The involvement of an apoptotic pathway in AZA1 cytotoxicity is complicated and as of yet unproven. For example, in vivo studies in mice exposed to AZA1 revealed severe effects such as deformation of intestinal epithelial villa as well as damage to $\mathrm{T}$ and $\mathrm{B}$ lymphocytes, development of lung tumors, and hyperplasia of the stomach lining. Apoptotic, spleen lymphocytes have been reported in mice exposed to AZA1. ${ }^{13,14}$ An in vitro study revealing upregulation of caspase activity in neuroblastoma cells ${ }^{20}$ and neocortical neurons ${ }^{19}$ was also supportive of apoptosis activation, although specific caspase pathways were not identified. However, results of an examination of mitochrondrial membrane potential in neuroblastoma cells were suggestive of a nonapoptotic pathway. ${ }^{34}$ Discrepancies with regard to whether AZA1 cytotoxicity is a regulated process may be explained, in part, by this toxin causing simultaneous induction of both apoptotic and necrotic mechanisms as suggested by Cao et al. ${ }^{19}$ This report adds to the growing body of AZA toxicity data and identifies several apoptotic indicators in three human cell lines.

\section{MATERIALS AND METHODS}

Toxin Isolation. The AZAs were isolated from cooked mussel tissue (Mytilus edulis) collected in 2005 from Bruckless, Donegal, Ireland. The AZAs were purified using a seven-step protocol, the details of which were reported by Kilcoyne et al. ${ }^{35}$ AZA purity (>95\%) was confirmed by LC-MS/MS and NMR spectroscopy. Stock AZA solutions were diluted in phosphate-buffered saline (PBS, pH 7.4) and $10 \%$ methanol. Methanol additions never exceeded $1 \%$ by volume.

Cell Culturing. Jurkat T lymphocyte (catalog no. TIB-152, ATCC, Manassas, VA), BE(2)-M17 neuroblastoma (catalog no. CRL-2267, ATCC), and intestinal epithelial Caco-2 (catalog no. HTB-37, ATCC) cell lines were maintained in culture at $5.0 \% \mathrm{CO}_{2}$ and $37{ }^{\circ} \mathrm{C}$ in a HERA Cell 150 incubator (Thermo Scientific, Rochester, NY). Cultures of nonadherent $\mathrm{T}$ lymphocyte cells were grown as described by Twiner et al. ${ }^{36}$ Neuroblastoma cells were grown in minimal essential medium/F-12 (catalog no. 30-2006, ATCC) supplemented with $10 \% \mathrm{FBS}$, and the intestinal epithelial cells were grown in minimal essential medium with Eagle salts (catalog no. 30-2003, ATCC) with $20 \%$ FBS. Adherent neuroblastoma and intestinal epithelial cells were subcultured when cells reached $80-90 \%$ confluence ( $4-7$ days). The cells were washed with PBS (catalog no. 30-2200, ATCC), released with $0.05 \%$ trypsin (catalog no. 25300 , GIBCO, Grand Island, NY), and resuspended in fresh medium. All cell lines were maintained in sterile $75 \mathrm{~cm}^{2}$ cell culture flasks.

Cytotoxicity Assay. Cells prepared for experimentation were diluted in fresh medium to a density of $250000 \mathrm{~T}$ lymphocyte cells/ $\mathrm{mL}, 100000$ intestinal cells $/ \mathrm{mL}$, and 150000 neuroblastoma cells $/ \mathrm{mL}$ before being distributed into 96-well plates. Each well contained 100 $\mu \mathrm{L}$ of cell solution. Cells were allowed to settle for $18-24 \mathrm{~h}$ prior to AZA additions to each set of three replicate wells for 24,48 , or $72 \mathrm{~h}$ of continuous exposure. The final concentration of AZA1 ranged from 0.001 to $94.8 \mathrm{nM}$. Control cells were exposed to an equivalent amount of a methanol/PBS solution. Final methanol concentrations never exceeded $1 \%$ by volume. Cellular viability or cytotoxicity was assessed using the MTS tetrazolium assay as previously described. ${ }^{36}$ The absorbance of each well was measured at $485 \mathrm{~nm}$ using a Fluostar microplate reader (BMG Technologies, Durham, NC). Data (means \pm $\mathrm{SE}$ ) from three or more independent experiments were normalized to percentage relative to controls.

Caspase Activity. Caspase activity in AZA1-treated cells was assayed using the Sensolyte AFC Caspase Sampler Kit (catalog no. 71117, Anaspec Inc., Fremont, CA) at three AZA concentrations (1,
10 , and $95 \mathrm{nM})$ at 24,48 , and $72 \mathrm{~h}$. Final methanol concentrations never exceeded $1 \%$ by volume. Procedures for the analysis of caspase activity were performed according to the manufacturer's protocol. Caspase activity was quantified through the use of eight 7-amino-4trifluoromethylcoumarin (AFC)-based peptide substrates. These substrates (substrate sequence in parentheses) were caspase-1 (AcYVAD and Ac-WEHD), caspase-2 (Ac-VDVAD), caspase-3/7 (AcDEVD and Z-DEVD), caspase-6 (Ac-VEID), caspase-8 (Ac-IETD), and caspase-9 (Ac-LEHD). Each caspase substrate was added directly into each cell well at a final concentration of $50 \mu \mathrm{M}$. Fluorescence was measured using the BMG FluoStar plate reader using excitation and emission wavelengths of 390 and $490 \mathrm{~nm}$, respectively, and recorded every $1 \mathrm{~min}$ for $2 \mathrm{~h}$. All data were first calculated in units of micromolar AFC per hour based on an AFC standard curve (range of 0.057-57 $\mu \mathrm{M}$ ) before normalization relative to control (\%). Camptothesin $(1 \mu \mathrm{M})$, a known apoptosis inducer, ${ }^{37,38}$ was used as a positive control. To assess caspase specificity in T lymphocyte cells, the irreversible broad-spectrum caspase inhibitor $1[100 \mu \mathrm{M}, \mathrm{Z}$ VAD(OMe)-FMK; catalog no. 627610, EMD Biosciences, San Diego, CA $)^{39}$ was added immediately prior to the caspase substrate.

Intracellular Cytochrome c. T lymphocyte cells were grown in six-well plates and treated with AZA1 $(95 \mathrm{nM})$ or equivalent amounts of a methanol vehicle. Final methanol concentrations were $1 \%$ by volume. At 24,48 , and $72 \mathrm{~h}$, cells were centrifuged ( $500 \mathrm{~g}$ for $10 \mathrm{~min}$ ) and washed twice with ice-cold PBS. The resulting cell pellets were stored at $-80{ }^{\circ} \mathrm{C}$ until they were used. Cell proteins were extracted on ice using cell extraction buffer (catalog no. FNN0011, Life Technologies, Carlsbad, CA) according to the manufacturer's instructions and stored at $-80{ }^{\circ} \mathrm{C}$. Cytochrome $c$ in the cell extracts was quantified using an ELISA kit (catalog no. KHO1051, Life Technologies) according to the manufacturer's instructions. Cytochrome $c(50-500 \mathrm{pg} / \mathrm{mL})$ was used as a standard. It should be noted that the cell extraction buffer contained detergents that may have solubilized membrane proteins such as cytochrome $c$ from a variety of subcellular compartments. As such, data are expressed as the total intracellular solubilized cytochrome $c$.

DNA Fragmentation. T lymphocyte cells were grown in 12-well plates and treated with AZA1 (1, 10, and $95 \mathrm{nM}), \mathrm{AZA} 2(10 \mathrm{nM})$, or AZA3 $(10 \mathrm{nM})$. A negative control of $10 \%$ methanol (in PBS) and positive controls of $10 \mathrm{nM}$ camptothesin or synthetic dinophysistoxin2 (DTX-2), known inducers of apoptosis, ${ }^{37,38,40,41}$ were also included. After $12,24,48$, and $72 \mathrm{~h}$, cells were centrifuged ( $500 \mathrm{~g}$ for $10 \mathrm{~min}$ ) and washed twice with ice-cold PBS. The resulting cell pellets were stored at $-80^{\circ} \mathrm{C}$. DNA was isolated using the QIAamp DNA Mini Kit (catalog no. 51304, Qiagen, Valencia, CA) according to the manufacturer's instructions. Purified DNA was eluted with $200 \mu \mathrm{L}$ of diethyl pyrocarbonate-treated water and concentrated with a Savant SpeedVac Concentrator to a volume of approximately $10-20 \mu \mathrm{L}$. DNA was quantified with a NanoDrop 2000 spectrophotometer (Thermo Scientific), and $1.5 \mu \mathrm{g}$ of each sample was loaded onto a $1.5 \%$ agarose gel and separated at $80 \mathrm{~V}$. Because of limited DNA recovery, the positive controls of camptothesin at 48 and $72 \mathrm{~h}$ had only $1.2 \mu \mathrm{g}$ while DTX2 at 48 and $72 \mathrm{~h}$ had only $0.7 \mu \mathrm{g}$. DNA was visualized with SYBR Safe DNA gel stain, and gel images were taken with the Kodak Gel Logic 100 Imaging System using Kodak MI version 4.0.3.

Statistical Analysis. Cytotoxicity, caspase, and cytochrome $c$ data are presented as means \pm SE of at least three independent experiments. In addition, each cytotoxicity and caspase experiment was performed using triplicate and duplicate wells, respectively. Cytotoxicity data were blank corrected and normalized to the vehicle control (\% viability). $\mathrm{EC}_{50}$ and $95 \%$ confidence interval determinations were calculated using three-parameter, variable-slope, nonlinear regression analysis (GraphPad Prism, version 5.0c, GraphPad, San Diego, CA). All fluorescence caspase data were first blank corrected and then converted into rates of AFC produced per hour. These values were statistically compared to the controls using one-way ANOVA with a Dunnett's post test using InStat version 3.0a (GraphPad) where $p<0.05$ was considered significant. Caspase data are illustrated as fold 
change relative to vehicle controls. Cytochrome $c$ data are presented as femtograms of cytochrome $c$ per cell.

\section{RESULTS}

Effect of AZA1 on Cell Viability. The three human cells types were exposed to various concentrations of AZA1 to assess viability and relative sensitivity. In each cell type, AZA1 caused time- and concentration-dependent cytotoxicity (Figure 1) that
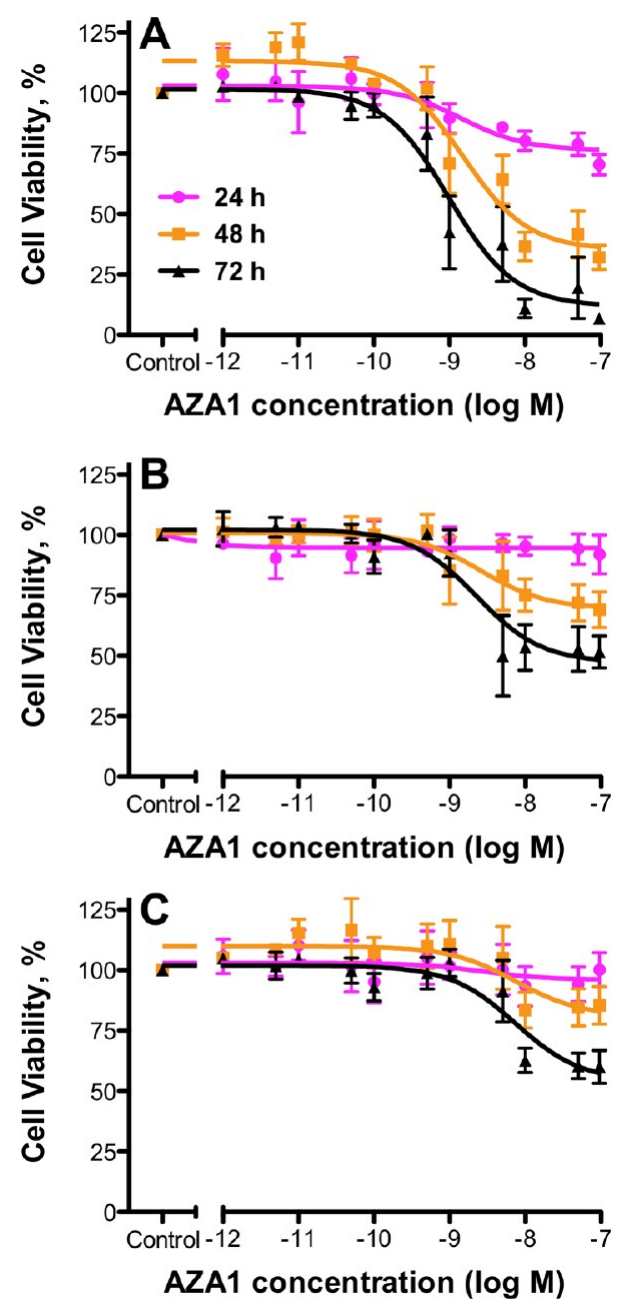

Figure 1. Effect of AZA1 on cell viability. (A) T lymphocyte, (B) intestinal, and (C) neuroblastoma cells were exposed to AZA1 for 24, 48 , or $72 \mathrm{~h}$, and viability was assessed using the MTS assay. All data (mean $\pm \mathrm{SE} ; n=3$ ) were normalized to the control (methanol vehicle) and analyzed using a nonlinear sigmoidal dose-response method (variable slope). Calculated $\mathrm{EC}_{50}$ values are shown (Table 1). Note that $\mathrm{EC}_{50}$ values were not calculated for the $24 \mathrm{~h}$ data in panels $\mathrm{B}$ and $\mathrm{C}$. are consistent with previous studies. ${ }^{16,22,28,36}$ At 24 h, AZA1 induced a $24 \%$ reduction in the viability of $\mathrm{T}$ lymphocytes, but no clear effects were observed in the neuroblastoma and intestinal cells (panels B and C of Figure 1, respectively). However, longer exposure times of 48 and $72 \mathrm{~h}$ markedly decreased the viability of each cell type. At AZA1 concentrations of $\geq 10 \mathrm{nM}$, T lymphocyte viability was reduced to 35 and $12 \%$ at 48 and $72 \mathrm{~h}$, respectively. At 48 and $72 \mathrm{~h}$, intestinal cell viability was 70 and $47 \%$ (Figure 1B) and neuroblastoma viability was 81 and $54 \%$ (Figure 1C), respectively. $\mathrm{EC}_{50}$ values (including $95 \%$ confidence intervals) are presented for each cell type at each time point in Table 1. The mean $\mathrm{EC}_{50}$ value for each cell type across all three time points was $1.1 \mathrm{nM}$ for T lymphocytes, $2.4 \mathrm{nM}$ for intestinal cells, and $7.4 \mathrm{nM}$ for neuroblastoma cells.

Effect of AZA1 on Caspase Activity. The effects of AZA1 on caspase activity were assessed in the three cell types with camptothesin used as a positive control. At $24 \mathrm{~h}$, AZA1 exposure did not alter the caspase activity of any cell type (Figures 2A, 3A, and 4A). At $48 \mathrm{~h}$, all tested AZA1 concentrations significantly increased the activity of caspase3/7 between 2.2- and 3.1-fold over the control (as determined using both Ac-DEVD and Z-DEVD substrate forms) in $\mathrm{T}$ lymphocytes (Figure 2B). Similarly, the activities of caspase-2 $(\sim 2.2$-fold $)$ and caspase-10 ( 1.8-fold $)$ were significantly elevated (Figure 2B). At $72 \mathrm{~h}$, caspase-3/7 activity was significantly elevated (average of $\sim 1.8$-fold for the two substrate forms) from treatments with 10 and $95 \mathrm{nM}$ AZA1 (Figure 2C). In the intestinal cells, AZA1 did not alter caspase activities at 48 h (Figure 3B), but by $72 \mathrm{~h}$, caspase-3/7 activity was significantly elevated (1.3-1.4-fold) in response to 10 and 95 nM AZA1 (Figure 3C). In neuroblastoma cells, caspase-3/7 activity was significantly elevated at 48 and $72 \mathrm{~h}$ (1.6-2.0-fold) for all AZA1 treatments (Figure 4B,C), while caspase- 2 activity was elevated in response to all AZA1 treatments at $72 \mathrm{~h}$ only (1.4-1.5-fold) (Figure 4C). Camptothesin significantly elevated the activities of all tested caspases in $\mathrm{T}$ lymphocytes and neuroblastoma cells but only those of caspase-1, caspase-3/7, and caspase-10 in the epithelial intestinal cells (Figures 2-4).

To confirm the elevated activities of caspase-2 and caspase-3/ 7 due to AZA1 exposure in T lymphocytes, similar experiments were performed in the presence of caspase inhibitor 1 . Similar to the data presented in Figure 2, AZA1 exposure resulted in elevated caspase-2 and caspase-3/7 activities (Figure 5). In these separate experiments, caspase- $3 / 7$ activity was not elevated at $24 \mathrm{~h}$ but was elevated by all AZA1 treatments at $48 \mathrm{~h}$ (1.6-3.4-fold) and $72 \mathrm{~h}$ (1.3-2.0-fold). However, in the presence of the inhibitor, the elevated activities of both caspases were nearly abolished to levels similar to the control. Significant reductions in caspase activity due to the inhibitor were observed at $48 \mathrm{~h}$ for both caspase- 2 and caspase- $3 / 7$ in cells exposed to 10 and $95 \mathrm{nM}$ AZA1 (Figure 5B). Inhibitor 1 also

Table 1. Cytotoxicity $\mathrm{EC}_{50}$ Values (nM; $n=3$ ) and 95\% Confidence Intervals (95\% CI) for T Lymphocyte, Intestinal, and Neuroblastoma Cells Exposed to AZA1

\begin{tabular}{|c|c|c|c|c|c|c|c|}
\hline \multirow[b]{2}{*}{ cell type } & \multicolumn{2}{|c|}{$24 \mathrm{~h}$} & \multicolumn{2}{|c|}{$48 \mathrm{~h}$} & \multicolumn{2}{|c|}{$72 \mathrm{~h}$} & \multirow[b]{2}{*}{ mean $\mathrm{EC}_{50}$} \\
\hline & $\mathrm{EC}_{50}$ & $95 \% \mathrm{CI}$ & $\mathrm{EC}_{50}$ & $95 \% \mathrm{CI}$ & $\mathrm{EC}_{50}$ & $95 \% \mathrm{CI}$ & \\
\hline T lymphocyte & 1.4 & $0.27-7.5$ & 1.5 & $0.68-3.2$ & 0.98 & $0.46-2.1$ & 1.1 \\
\hline intestinal & not applicable & & 2.6 & $0.46-14$ & 2.3 & $0.84-6.1$ & 2.4 \\
\hline neuroblastoma & not applicable & & 7.5 & $0.83-67$ & 7.4 & $2.6-21$ & 7.4 \\
\hline
\end{tabular}



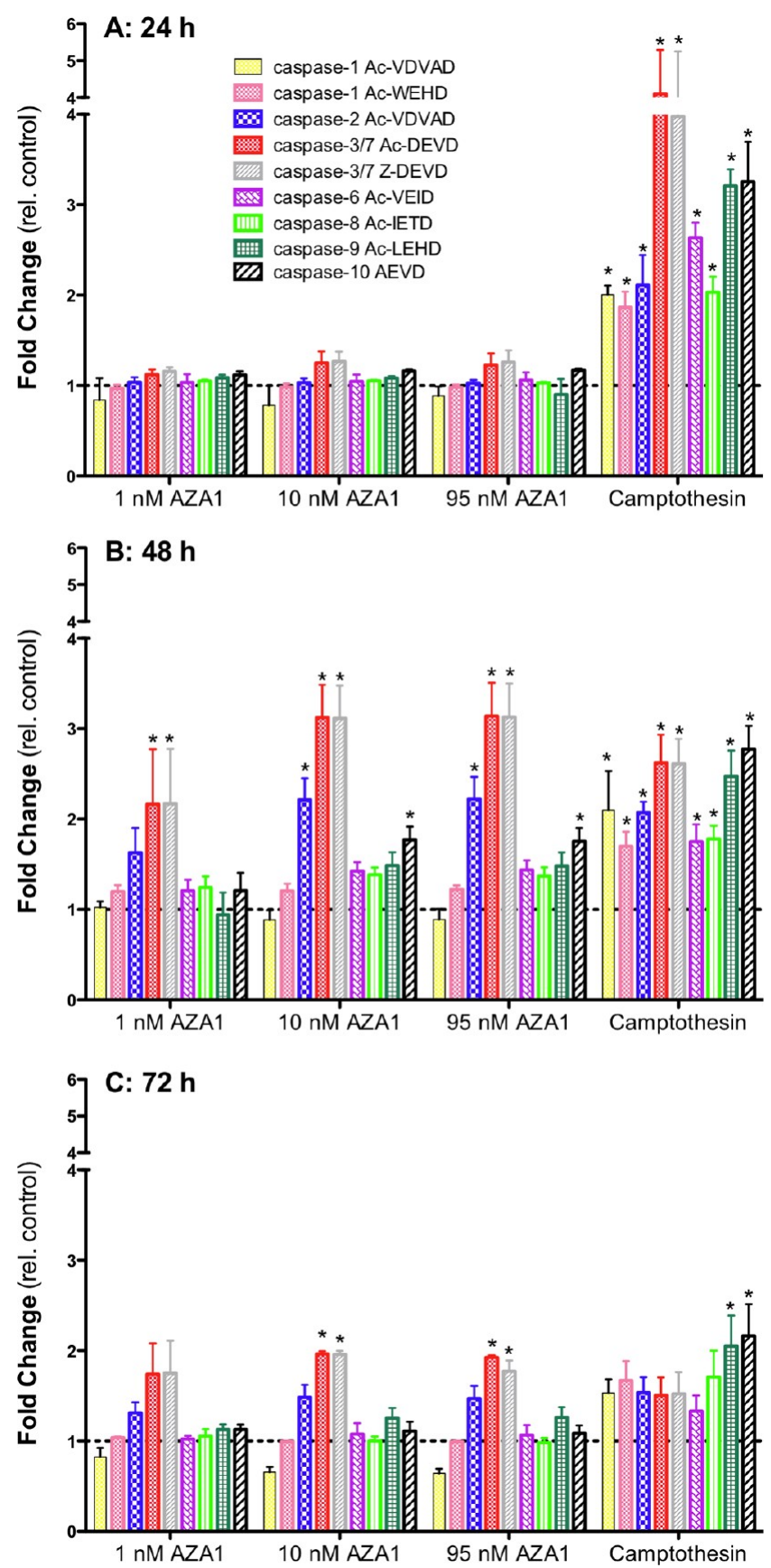

Figure 2. Upregulation of caspases in $\mathrm{T}$ lymphocyte cells following exposure to AZA1. Cells were exposed to 1,10 , and $95 \mathrm{nM}$ AZA1 for (A) 24, (B) 48, or (C) $72 \mathrm{~h}$ before caspase activity was determined. Caspase activity data (mean $\pm \mathrm{SE} ; n=3$ ) are expressed as the fold change relative to control. Camptothesin $(1 \mu \mathrm{M}$ in DMSO; a known apoptosis inducer) was the positive control. AZA vehicle controls were $0.1 \%$ methanol, and camptothesin vehicle controls were $1 \%$ DMSO (final concentration). Asterisks denote data with a significant difference $(p<0.05)$ relative to the appropriate vehicle control.

caused a significant reduction in the activity of caspase-3/7 at $72 \mathrm{~h}$ in cells exposed to $10 \mathrm{nM}$ AZA1 (Figure 5C).

Effects of AZA1 on Intracellular Cytochrome c. The release of cytochrome $c$ from the inner membrane of the mitochondria into the cytosol is an indicator of mitochrondrially dependent apoptosis. In this manner, cytochrome $c$ is also called apoptotic protease activating factor 2 (Apaf 2). In $\mathrm{T}$ lymphocyte cells exposed to AZA1 (95 nM) for up to $72 \mathrm{~h}$,
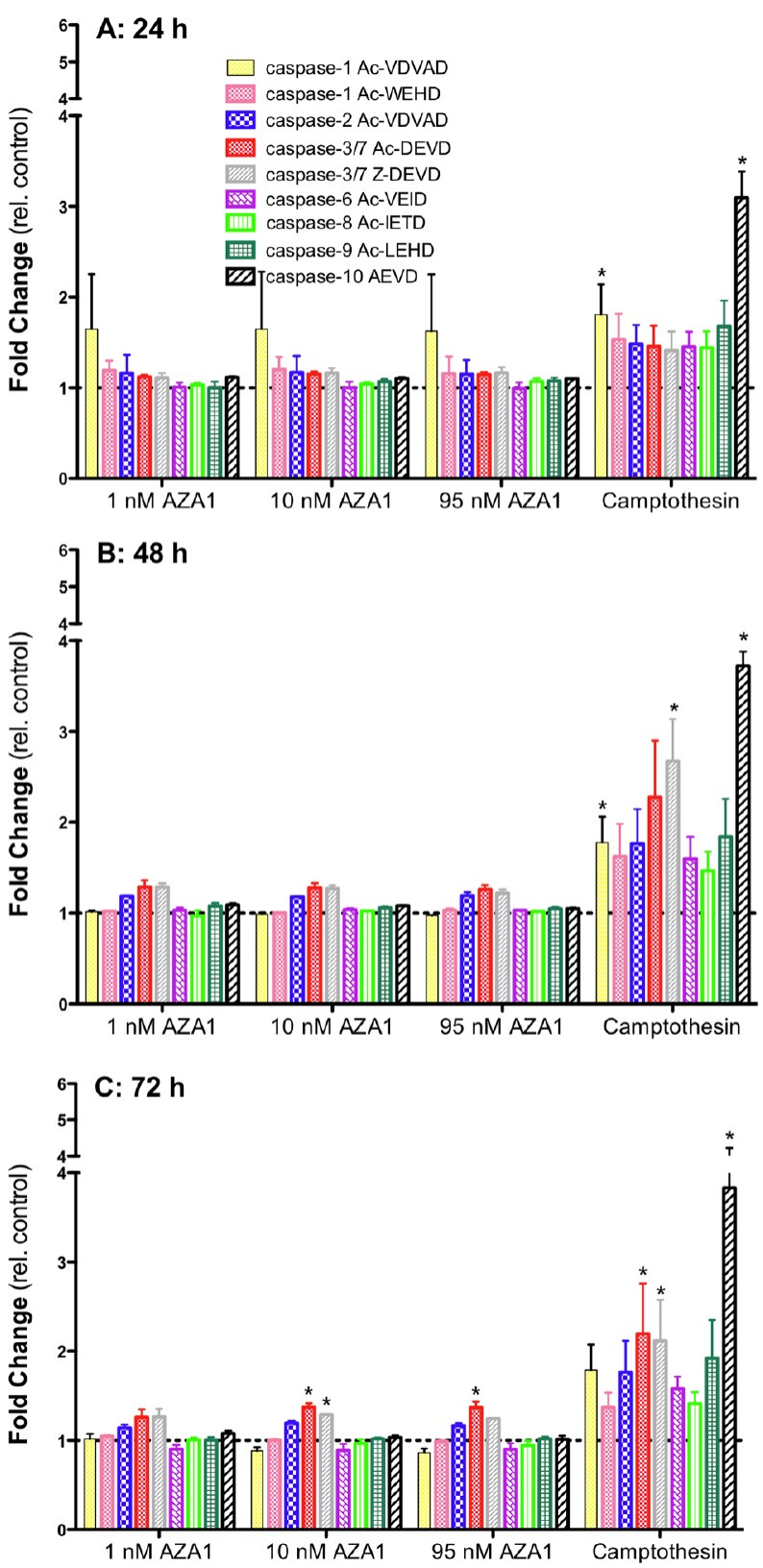

Figure 3. Upregulation of caspases in Caco-2 epithelial cells following exposure to AZA1. Cells were exposed to 1,10 , and $95 \mathrm{nM}$ AZA1 for (A) 24, (B) 48, or (C) $72 \mathrm{~h}$ before caspase activity was determined. Caspase activity data (mean $\pm \mathrm{SE} ; n=3$ ) are expressed as the fold change relative to control. Camptothesin ( $1 \mu \mathrm{M}$ in DMSO; a known apoptosis inducer) was the positive control. AZA vehicle controls were $0.1 \%$ methanol, and camptothesin vehicle controls were $1 \%$ DMSO (final concentration). Asterisks denote data with a significant difference $(p<0.05)$ relative to the appropriate vehicle control.

total intracellular solubilized levels of cytochrome $c$ were significantly elevated above those of parallel control cells (Figure 6). Control cells consistently contained $0.7-0.8 \mathrm{fg} / \mathrm{cell}$, whereas cells treated with AZA1 contained between 2.4 and 6.7 $\mathrm{fg} /$ cell. Relative to the control, AZA1-treated cells contained 3-, 4 -, and 7-fold more cytochrome $c$ at 24, 48, and 72 h; respectively.

Effects of AZAs on DNA Fragmentation. The fragmentation of DNA (i.e., laddering) is a common hallmark of cells undergoing late-stage apoptosis. $\mathrm{T}$ lymphocyte cells exposed to AZA1 (1, 10, and $95 \mathrm{nM}), \operatorname{AZA} 2(10 \mathrm{nM})$, and 

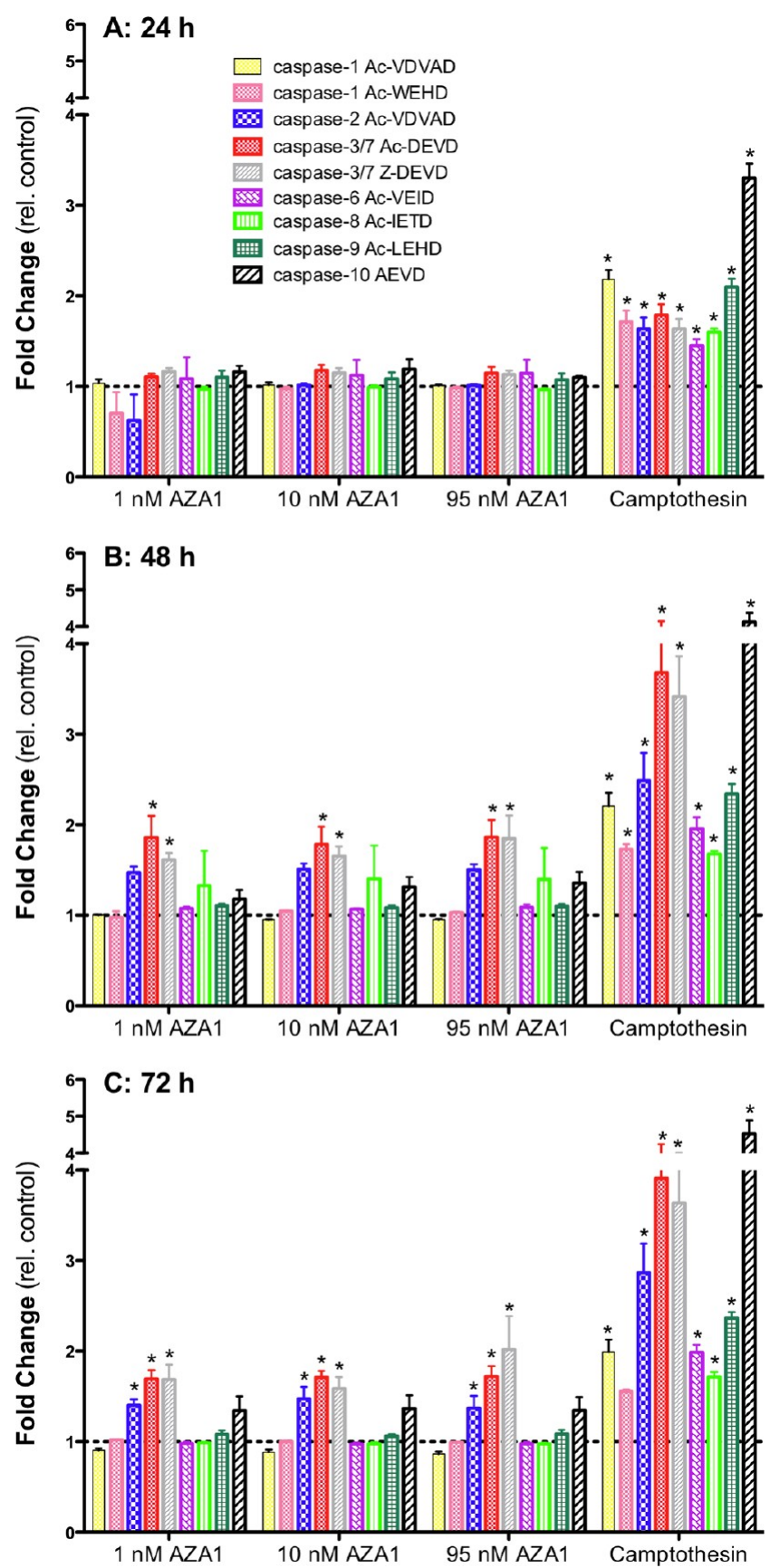

Figure 4. Upregulation of caspases in BE(2)-M17 neuroblastoma cells following exposure to AZA1. Cells were exposed to 1, 10, and $95 \mathrm{nM}$ AZA1 for (A) 24, (B) 48, or (C) $72 \mathrm{~h}$ before caspase activity was determined. Caspase activity data (mean $\pm \mathrm{SE} ; n=3$ ) are expressed as the fold change relative to control. Camptothesin ( $1 \mu \mathrm{M}$ in DMSO; a known apoptosis inducer) was the positive control. AZA vehicle controls were $0.1 \%$ methanol, and camptothesin vehicle controls were $1 \%$ DMSO (final concentration). Asterisks denote data with a significant difference $(p<0.05)$ relative to the appropriate vehicle control.

AZA3 (10 nM) were assessed for DNA laddering at 12, 24, 48, and $72 \mathrm{~h}$. Although no laddering was observed for any of the AZA treatments at 12 and $24 \mathrm{~h}$ (Figure 7A,B), laddering was observed for all AZA treatments at 48 and $72 \mathrm{~h}$ (Figure 7C,D). The positive control camptothesin resulted in DNA laddering at $12 \mathrm{~h}$, and DTX2 resulted in laddering at 12,24 , and $48 \mathrm{~h}$. No
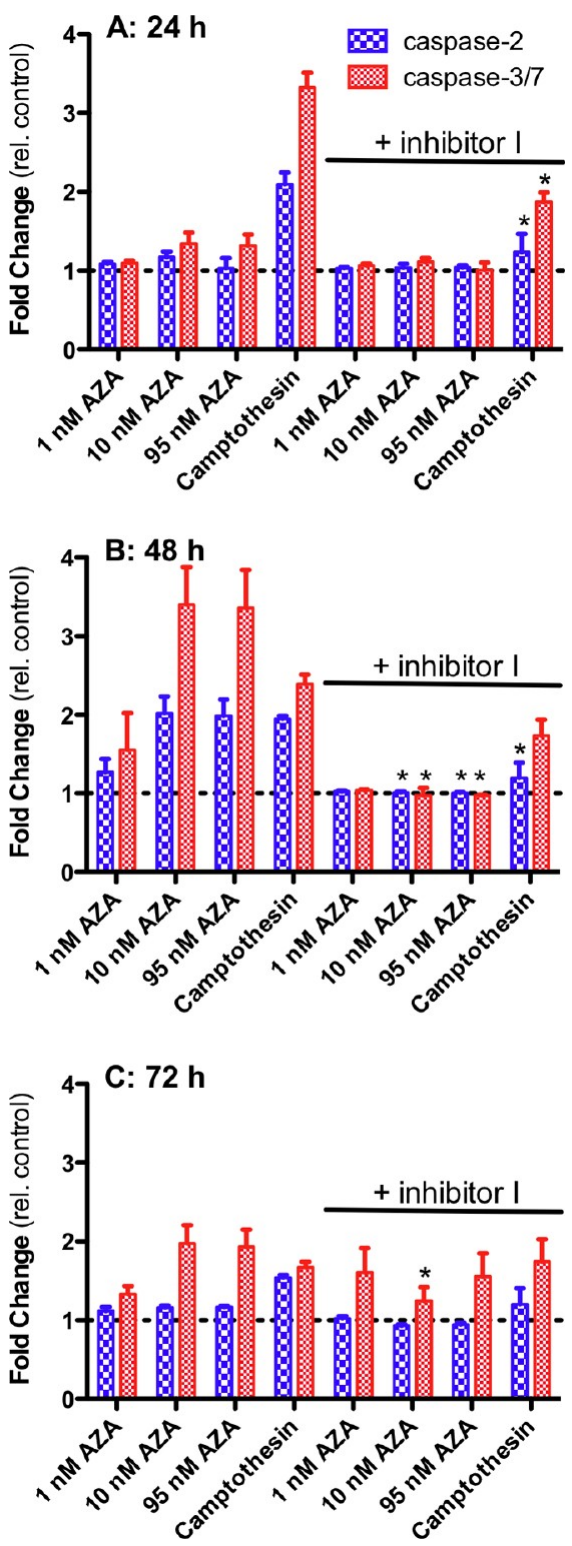

Figure 5. Inhibition of AZA1-induced upregulation of caspases in T lymphocyte cells. Cells were exposed to 1,10 , and $95 \mathrm{nM}$ AZA1 for (A) 24, (B) 48, or (C) $72 \mathrm{~h}$ before caspase- 2 and caspase-3/7 (AcDEVD) activity was determined in the presence or absence of inhibitor $1(100 \mu \mathrm{M}) .{ }^{39}$ Data (mean $\pm \mathrm{SE}$; $\left.n=3\right)$ are expressed as the rate of cleavage of fluorescent $\mathrm{AFC}$ from added substrate (micromolar per hour) relative to control. Camptothesin $(1 \mu \mathrm{M}$ in DMSO; a known apoptosis inducing compound) served as the positive control. AZA vehicle controls were $0.1 \%$ methanol, and camptothesin vehicle controls were $1 \%$ DMSO (final concentration). Asterisks denote data with a significant difference $(p<0.05)$ between caspase activities in the presence and absence of the inhibitor.

laddering was observed in methanol controls (Figure 7) or DMSO controls (data not shown).

\section{DISCUSSION}

AZAs are potent cytotoxins toward nearly every cell type tested thus far. $6,16,19,20,22,36,42$ However, the various cell types are differentially sensitive with cytotoxic $\mathrm{EC}_{50}$ concentrations ranging from low nanomolar to hundreds of nanomolar. In this study, the cytotoxic potential of AZA1 toward three different cell lines was confirmed, ${ }^{22,28,36}$ and relative potencies 


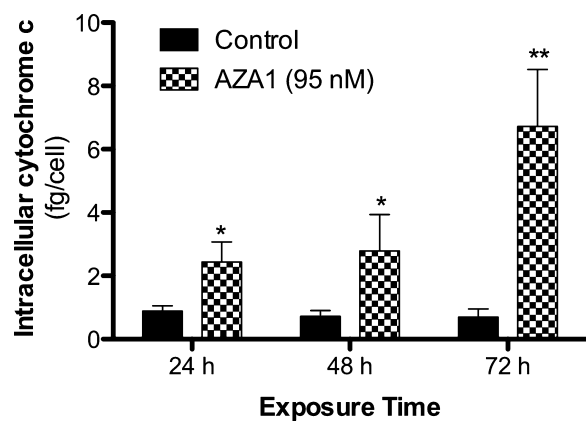

Figure 6. Effects of AZA1 on intracellular cytochrome $c$ in $\mathrm{T}$ lymphocyte cells. Cells were exposed to $95 \mathrm{nM}$ AZA1 for 24,48 , or 72 $\mathrm{h}$ before cells were collected and levels of intracellular solubilized cytochrome $c$ were determined. Data (mean \pm SE; $n=3$ ) are expressed as femtograms of cytochrome $c$ per cell. AZA1 vehicle controls were $1 \%$ methanol. Asterisks denote data with a significant difference $(p<0.05)$ relative to the vehicle control at a given time point.

were determined. On the basis of $\mathrm{EC}_{50}$ values determined in this study, $\mathrm{T}$ lymphocytes (Jurkat) were the most sensitive (mean $\mathrm{EC}_{50}$ of $1.1 \mathrm{nM}$ ), followed by intestinal cells (Caco-2; mean $\mathrm{EC}_{50}$ of $2.4 \mathrm{nM}$ ) and neuroblastoma cells [BE(2)-M17; mean $\mathrm{EC}_{50}$ of $\left.7.4 \mathrm{nM}\right]$. Consistent with previous AZA1 studies, an increased time of exposure to AZA1 affected cell viability but did not change the calculated $\mathrm{EC}_{50}$ values for time points up to $72 \mathrm{~h}^{16,36}$ Gross differences were observed between the cells lines upon comparison of maximal cytotoxicity. Protracted exposures of T lymphocytes to high AZAl concentrations $(\geq 50$ $\mathrm{nM}$ ) resulted in $90 \%$ cytotoxicity, whereas the intestinal and neuroblastoma cells experienced 53 and $46 \%$ cytotoxicity, respectively. The suppression of neuroblastoma cell viability is consistent with proliferation studies employing a $50 \mathrm{nM}$ AZA1 exposure for $48 \mathrm{~h}^{22}$

Morphological observations by other investigators do not provide a consistent pattern for the mechanism of cytotoxicity. $\mathrm{T}$ lymphocytes and Caco-2 intestinal cells exposed to AZA1 (and/or AZA2 and AZA3) do not exhibit the classical features of apoptosis. ${ }^{16,22,36}$ However, morphologies of AZA1-treated $\mathrm{BE}(2)-\mathrm{M} 17$ neuroblastoma cells and primary cerebellar granule cells (CGCs) have been shown to be consistent with cells undergoing apoptosis, ${ }^{20,22,42}$ with the neuroblastoma cells having upregulated caspase-1 and $-3-9$ activity. ${ }^{20}$ CGCs exposed to AZA1 have also shown significant changes in nuclear morphology, with more than $62 \%$ of the cells deemed as apoptotic by Hoechst staining and caspase- 3 activity severalfold higher than that of control cells. ${ }^{19}$ Similarly, dead or dying lymphocyte cells in the spleen and thymus of mice exposed to AZA1 have been observed undergoing pyknosis-chromatin condensation indicative of apoptosis. ${ }^{43}$

In addition to confirming the cytotoxic potential of AZAs, this study has broadly assessed the effects of AZA1 on seven different caspases in three different cell types followed by an evaluation of the effects of AZA1 on intracellular cytochrome $c$ and DNA fragmentation in T lymphocyte cells. Across all cell types, we consistently observed significant elevations in the activity of caspase-3/7 following AZA1 exposure. Caspase-3 and caspase- 7 are effector caspases that, once activated, are directly responsible for cell shrinkage and membrane blebbing as well as nuclear DNA fragmentation. ${ }^{32,44}$ Despite the absence of cell shrinkage and membrane blebbing in T lymphocytes, ${ }^{36}$ late stage DNA laddering was clearly evident.
Caspase- 2 activity was also elevated in $\mathrm{T}$ lymphocytes and neuroblastoma cells, while an elevation of caspase-10 activity was observed only in T lymphocytes. Caspase- 2 is an initiator caspase activated via a receptor and/or stress response ${ }^{45,46}$ within the intrinsic caspase cascade (mitochondrial apoptotic pathway). ${ }^{47}$ Caspase- 2 typically induces the release of cytochrome $c$ from the mitochondria and then activates caspase-3 via caspase-9-dependent or -independent pathways. ${ }^{48}$ Because caspase- 9 was not affected by AZA1, it appears as though AZA1 triggers apoptosis via a caspase-9-independent mitochrondrial pathway, possibly similar to the activation pathway involving tumor necrosis factor- $\alpha$ (TNF- $\alpha){ }^{48}$ Although much less is known about caspase-10, it is an initiator caspase associated with the Fas-associated protein with death domain (FADD) receptors. ${ }^{49}$ The involvement of multiple caspases in the cytotoxic response supports the findings of Cao et al. ${ }^{19}$ that AZA1-induced cytotoxicity in CGCs was partially attenuated through the use of a caspase- 3 inhibitor and complete cellular protection was provided when a broad-spectrum caspase inhibitor was used. Although this study did not investigate the ability of caspase inhibitors to rescue cells and/or ameliorate other apoptotic end points, we did confirm that a broad-spectrum caspase inhibitor was able to inhibit the elevated caspase activity of $\mathrm{T}$ lymphocytes.

The release of cytochrome $c$ from mitochondria from the outer surface of the inner mitochrondrial membrane has been identified as an apoptotic protease activating factor 2 (Apaf 2) that typically results in the formation of a complex between Apaf 1 and caspase-9 (Apaf 3). In turn, the complex activates caspase- 3 that leads to DNA fragmentation and apoptosis. ${ }^{50-52}$ From our experiments using $\mathrm{T}$ lymphocyte cells, high concentrations of AZA1 appear to induce a time-dependent increase in the total intracellular levels of solubilized of cytochrome $c$ that temporally coincide with the fragmentation of nuclear DNA. However, considering the extraction methods utilized, we cannot specifically ascertain whether the AZAinduced increase in the level of intracellular solubilized cytochrome $c$ occurred via release from mitochondria or other subcellular components.

Although this report does not provide evidence of the sequence of apoptotic events, we have shown that AZA1 induces many of the steps common to apoptotic cell death and provide a working model for future AZA apoptosis studies. Our working model includes upregulation of caspase-10 and caspase-2, elevated levels of intracellular solubilized cytochrome c, activation of effector caspase- 3 and caspase-7, fragmentation of nuclear DNA, and cytotoxicity. The sensitivity of $\mathrm{T}$ lymphocytes for studying these pathways relative to the other cell lines may be due to a higher level of expression of a molecular target that is constitutively present in the $T$ lymphocyte cells. However, this tentative hypothesis may now be tested because AZA1-AZA3 have each been shown to be open state blockers of hERG potassium channels. ${ }^{30}$ Coincidently, many hERG channel inhibitors are also known inducers of caspase-3-dependent ${ }^{53}$ apoptosis ${ }^{54}$ and can cause cytotoxicity toward a wide variety of cell lines. ${ }^{55,56}$

Interpretation of AZA mechanistic studies is complicated by the growing body of evidence suggesting that the various AZA analogues may have more than one molecular target and may act upon these targets differently. ${ }^{19,24,36}$ The existence of distinct molecular targets may also help explain the simultaneous appearance of cellular markers for both apoptosis and necrosis across different cell lines $\mathrm{s}^{6,19,20,34}$ and following in 

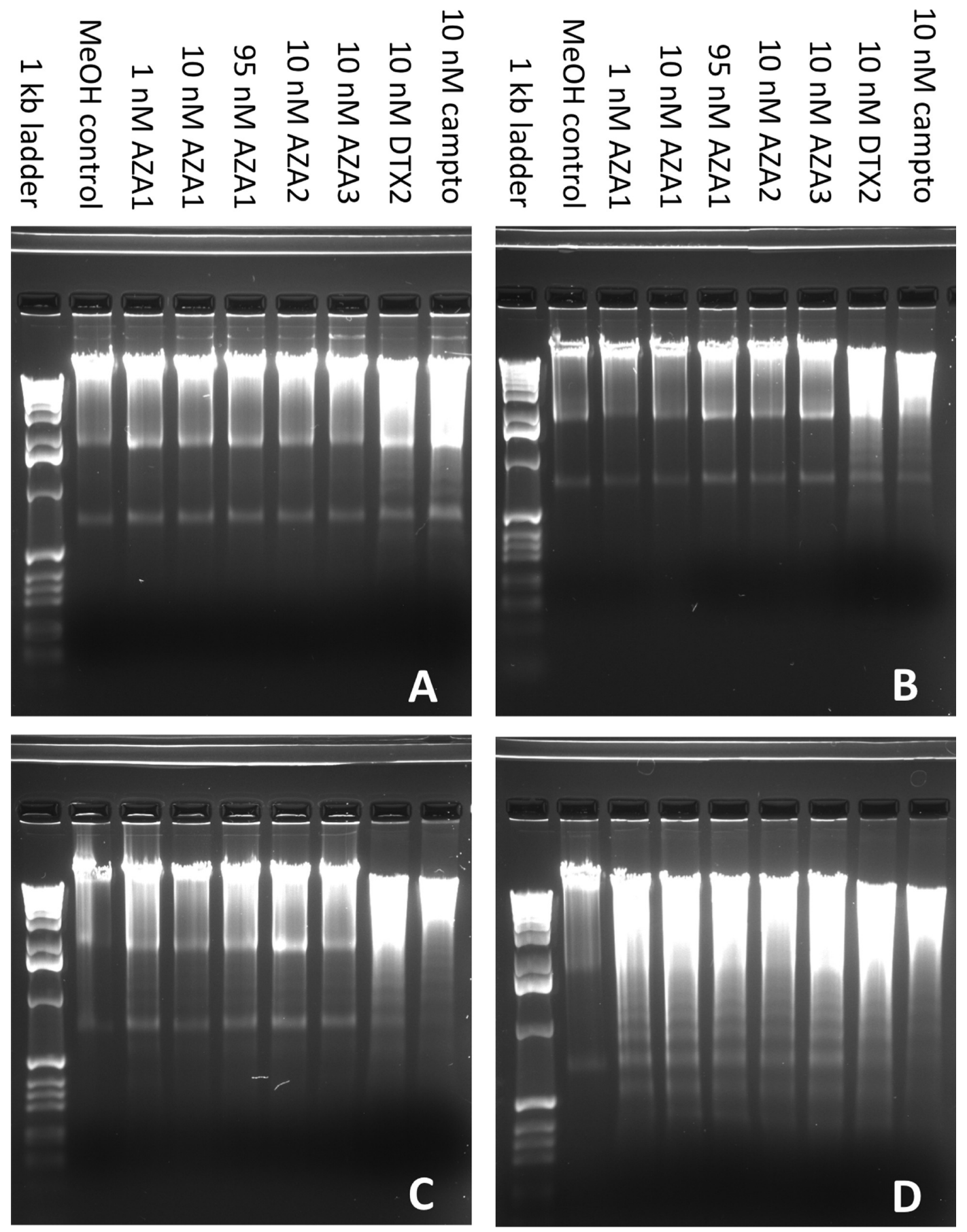

Figure 7. Effects of AZA analogues on DNA fragmentation of T lymphocyte cells. Cells were exposed to 1, 10, and $95 \mathrm{nM}$ AZA1, $10 \mathrm{nM}$ AZA2, or $10 \mathrm{nM}$ AZA3 for (A) 12, (B) 24, (C) 48, or (D) $72 \mathrm{~h}$. Camptothesin (campto, $10 \mathrm{nM}$ ) and synthetic DTX2 (10 nM) served as positive controls, and AZA vehicle controls were $0.1 \%$ methanol.

vivo AZA1 exposure. ${ }^{13,14,43}$ This is quite possible as overlaps exist between cellular responses within the necrotic and apoptotic pathways. ${ }^{57,58}$ In particular, some caspases such as caspase- 8 appear to have multiple functions beyond just those associated with apoptosis. ${ }^{58}$

Although clearly requiring additional investigation, our DNA laddering data suggest that AZA2 and AZA3 may also induce apoptosis in $\mathrm{T}$ lymphocytes. This is interesting in that AZA2 and AZA3, similar to AZA1, do not induce any of the classical morphological features associated with apoptosis ${ }^{36}$ but have been shown to induce 4-fold upregulation of caspase-3 in CGCs. ${ }^{19}$

\section{CONCLUSIONS}

In summary, we have corroborated previous studies showing that that AZA1 is highly cytotoxic to T lymphocytes, ${ }^{16,34,36}$ intestinal cells, ${ }^{22,28}$ and neuroblastoma cells. ${ }^{20,22}$ In $\mathrm{T}$ lymphocytes, AZA1 causes the upregulation of initiator caspase-2 and -10, elevations in levels of intracellular cytochrome $c$, and activation of effector caspase-3 and caspase-7. Peak activities of caspase- 3 and caspase-7 correspond 
to the time points and AZA1 concentrations associated with nuclear DNA fragmentation and cytotoxicity. These findings are consistent with previous studies that suggest the cellular pathways resulting in AZA1-induced cytotoxicity are a combination of both necrosis and apoptosis.

\section{AUTHOR INFORMATION}

\section{Corresponding Author}

*Department of Natural Sciences, University of MichiganDearborn, 4901 Evergreen Rd., Dearborn, MI 48128. Phone: (313) 593-5298. Fax: (313) 593-4937. E-mail: mtwiner@umd. umich.edu.

\section{Funding}

This work (Grant-Aid Agreement 221117) was supported by the Sea Change strategy with the support of the Marine Institute and the Marine Research Subprogram of National Development Plan 2007-2013, cofinanced under the European Regional Development Fund; a National Science FoundationResearch Experience for Undergraduates Grant (DBI0552828); the U.S. Department of Defense A.S.S.URE Program; a University of Michigan-Dearborn Office of Research and Sponsored Programs Faculty Initiation and Seed Grant; and NOAA/NOS operational funds.

\section{Notes}

The authors declare no competing financial interest.

\section{ACKNOWLEDGMENTS}

Special thanks go to Jane Kilcoyne, Chris Miles, Philipp Hess, Adela Keogh, Conor Duffy, Ger Clancy, Pearse McCarron, Nils Rehmann, Thierry Jauffrais, Daniel o'Driscoll, and Michael Quilliam for AZA purification. This publication does not constitute an endorsement of any commercial product or intend to be an opinion beyond scientific or other results obtained by the National Oceanic and Atmospheric Administration (NOAA). No reference shall be made to NOAA, or this publication furnished by NOAA, to any advertising or sales promotion which would indicate or imply that NOAA recommends or endorses any proprietary product mentioned herein, or which has as its purpose an interest to cause the advertised product to be used or purchased because of this publication.

\section{ABBREVIATIONS}

AFC, 7-amino-4-trifluoromethylcoumarin; Apaf, apoptotic protease activating factor; AZA, azaspiracid; CGCs, cerebellar granule cells; DTX2, dinophysistoxin-2; $\mathrm{EC}_{50}, 50 \%$ maximal effective concentration; FADD, Fas-associated protein with a death domain; FBS, fetal bovine serum; LC-MS/MS, liquid chromatography-tandem mass spectrometry; MTS, 3-(4,5dimethylthiazol-2-yl)-5-(3-carboxymethoxyphenyl)-2-(4-sulfophenyl)-2H-tetrazolium; NMR, nuclear magnetic resonance; PBS, phosphate-buffered saline; TNF, tumor necrosis factor.

\section{REFERENCES}

(1) McMahon, T., and Silke, J. (1996) Winter toxicity of unknown aetiology in mussels. Harmful Algae News 14, 2.

(2) Satake, M., Ofuji, K., Naoki, H., James, K. J., Furey, A., McMahon, T., Silke, J., and Yasumoto, T. (1998) Azaspiracid, a new marine toxin having unique spiro ring assemlies, isolated from Irish mussels, Mytilus edulis. J. Am. Chem. Soc. 120, 9967-9968.

(3) Furey, A., O'Doherty, S., O'Callaghan, K., Lehane, M., and James, K. J. (2010) Azaspiracid poisoning (AZP) toxins in shellfish: Toxicological and health considerations. Toxicon 56, 173-190.
(4) Taleb, H., Vale, P., Amanhir, R., Benhadouch, A., Sagou, R., and Chafik, A. (2006) First detection of azaspiracids in mussels in north west Africa. J. Shellfish Res. 25, 1067-1070.

(5) Klontz, K. C., Abraham, A., Plakas, S. M., and Dickey, R. W. (2009) Mussel-associated azaspiracid intoxication in the United States. Ann. Intern. Med. 150, 361.

(6) Twiner, M. J., Rehmann, N., Hess, P., and Doucette, G. J. (2008) Azaspiracid shellfish poisoning: A review on the chemistry, ecology, and toxicology with an emphasis on human health impacts. Mar. Drugs $6,39-72$.

(7) Colman, J. R., Twiner, M. J., Hess, P., McMahon, T., Satake, M., Yasumoto, T., Doucette, G. J., and Ramsdell, J. S. (2005) Teratogenic effects of azaspiracid-1 identified by microinjection of Japanese medaka (Oryzias latipes) embryos. Toxicon 45, 881-890.

(8) Hess, P., McCarron, P., Rehmann, N., Kilcoyne, J., McMahon, T., Ryan, G., Ryan, P. M., Twiner, M. J., Doucette, G. J., Satake, M., Ito, E., and Yasumoto, T. (2007) Isolation and purification of azaspiracids from naturally contaminated materials, and evaluation of their toxicological effects. Final project report ASTOX (ST/02/02), p 129, Marine Environment \& Health Series, Marine Institute, Rinville, Co. Galway.

(9) James, K. J., Sierra, M. D., Lehane, M., Braña Magdalena, A., and Furey, A. (2003) Detection of five new hydroxyl analogues of azaspiracids in shellfish using multiple tandem mass spectrometry. Toxicon 41, 277-283.

(10) Rehmann, N., Hess, P., and Quilliam, M. (2008) Discovery of new analogs of the marine biotoxin azaspiracid in blue mussels (Mytilus edulis) by ultra-performance liquid chromatography/tandem mass spectrometry. Rapid Commun. Mass Spectrom. 22, 549-558.

(11) Krock, B., Tillmann, U., John, U., and Cembella, A. D. (2009) Characterization of azaspiracids in plankton size-fractions and isolation of an azaspiracid-producing dinoflagellate from the North Sea. Harmful Algae 8, 254-263.

(12) Tillmann, U., Elbrächter, M., Krock, B., John, U., and Cembella, A. (2009) Azadinium spinosum gen. et sp. nov. (Dinophyceae) identified as a primary producer of azaspiracid toxins. Eur. J. Phycol. 44, $63-79$.

(13) Ito, E., Satake, M., Ofuji, K., Higashi, M., Harigaya, K., McMahon, T., and Yasumoto, T. (2002) Chronic effects in mice caused by oral administration of sublethal doses of azaspiracid, a new marine toxin isolated from mussels. Toxicon 40, 193-203.

(14) Ito, E., Satake, M., Ofuji, K., Kurita, N., McMahon, T., James, K., and Yasumoto, T. (2000) Multiple organ damage caused by a new toxin azaspiracid, isolated from mussels produced in Ireland. Toxicon 38, 917-930.

(15) Ito, E., Terao, K., McMahon, T., Silke, J., and Yasumoto, T. (1998) Acute pathological changes in mice caused by crude extracts of novel toxins isolated from Irish mussels. In Harmful Algae (Reguera, B., Blanco, J., Fernandez, M. L., and Wyatt, T., Eds.) pp 588-589, Xunta de Galicia and Intergovernmental Oceanographic Commission of UNESCO, Santiago de Compostela.

(16) Twiner, M. J., Hess, P., Bottein Dechraoui, M.-Y., McMahon, T., Samons, M. S., Satake, M., Yasumoto, T., Ramsdell, J. S., and Doucette, G. J. (2005) Cytotoxic and cytoskeletal effects of azaspiracid-1 on mammalian cell lines. Toxicon 45, 891-900.

(17) Ueoka, R., Ito, A., Izumikawa, M., Maeda, S., Takagi, M., Shinya, K., Yoshida, M., van Soest, R. W. M., and Matsunaga, S. (2009) Isolation of azaspiracid-2 from a marine sponge Echinoclathria sp. as a potent cytotoxin. Toxicon 53, 680-684.

(18) Vale, C., Nicolaou, K. C., Frederick, M. O., Gomez-Limia, B., Alfonso, A., Vieytes, M. R., and Botana, L. M. (2007) Effects of azaspiracid-1, a potent cytotoxic agent, on primary neuronal cultures. A structure-activity relationship study. J. Med. Chem. 50, 356-363.

(19) Cao, Z., LePage, K. T., Frederick, M. O., Nicolaou, K. C., and Murray, T. F. (2010) Involvement of caspase activation in azaspiracidinduced neurotoxicity in neocortical neurons. Toxicol. Sci. 114, 323334.

(20) Vilariño, N., Nicolaou, K. C., Frederick, M. O., Vieytes, M. R., and Botana, L. M. (2007) Irreversible cytoskeletal disarrangement is 
independent of caspase activation during in vitro azaspiracid toxicity in human neuroblastoma cells. Biochem. Pharmacol. 74, 327-335.

(21) Vilariño, N. (2008) Marine toxins and the cytoskeleton: azaspiracids. FEBS J. 275, 6075-6081.

(22) Vilariño, N., Nicolaou, K. C., Frederick, M. O., Cagide, E., Ares, I. R., Louzao, M. C., Vieytes, M. R., and Botana, L. M. (2006) Cell growth inhibition and actin cytoskeleton disorganization induced by azaspiracid-1 structure-activity studies. Chem. Res. Toxicol. 19, 14591466.

(23) Alfonso, A., Roman, Y., Vieytes, M. R., Ofuji, K., Satake, M., Yasumoto, T., and Botana, L. M. (2005) Azaspiracid-4 inhibits $\mathrm{Ca}^{2+}$ entry by stored operated channels in human T lymphocytes. Biochem. Pharmacol. 69, 1627-1636.

(24) Roman, Y., Alfonso, A., Vieytes, M. R., Ofuji, K., Satake, M., Yasumoto, T., and Botana, L. M. (2004) Effects of azaspiracids 2 and 3 on intracellular cAMP, $\left[\mathrm{Ca}^{2+}\right]$, and pH. Chem. Res. Toxicol. 17, 13381349.

(25) Kellmann, R., Schaffner, C. A. M., Grønset, T. A., Satake, M., Ziegler, M., and Fladmark, K. E. (2009) Proteomic response of human neuroblastoma cells to azaspiracid-1. J. Proteomics 72, 695-707.

(26) Kulagina, K. V., Twiner, M. J., Hess, P., McMahon, T., Satake, M., Yasumoto, T., Ramsdell, J. S., Doucette, G. J., Ma, W., and O'Shaughnessy, T. J. (2006) Azaspiracid-1 inhibits bioelectrical activity of spinal cord neuronal networks. Toxicon 47, 766-773.

(27) Bellocci, M., Sala, G. L., Callegari, F., and Rossini, G. P. (2010) Azaspiracid-1 inhibits endocytosis of plasma membrane proteins in epithelial cells. Toxicol. Sci. 117, 109-121.

(28) Ronzitti, G., Hess, P., Rehmann, N., and Rossini, G. P. (2007) Azaspiracid-1 alters the E-cadherin pool in epithelial cells. Toxicol. Sci. 95, 427-435.

(29) Twiner, M. J., Ryan, J. C., Morey, J. S., Smith, K. J., Hammad, S. M., Van Dolah, F. M., Hess, P., McMahon, T., Satake, M., Yasumoto, T., and Doucette, G. J. (2008) Transcriptional profiling and inhibition of cholesterol biosynthesis in human lymphocyte $\mathrm{T}$ cells by the marine toxin azaspiracid. Genomics 91, 289-300.

(30) Twiner, M. J., Doucette, G. J., Rasky, A., Huang, X.-P., Roth, B. L., and Sanguinetti, M. C. (2012) The marine algal toxin azaspiracid is an open state blocker of hERG potassium channels. Toxicol. Sci. (manuscript under review).

(31) Hengartner, M. D. (1992) The biochemistry of apoptosis. Nature 407, 770-776.

(32) McConkey, D. J. (1998) Biochemical determinants of apoptosis and necrosis. Toxicol. Lett. 99, 157-168.

(33) Elmore, S. (2007) Apoptosis: A review of programmed cell death. Toxicol. Pathol. 35, 495-516.

(34) Roman, Y., Alfonso, A., Louzao, M. C., de la Rosa, L. A., Leira, F., Vieites, J. M., Vieytes, M. R., Ofuji, K., Satake, M., Yasumoto, T., and Botana, L. M. (2002) Azaspiracid-1, a potent, nonapoptotic new phycotoxin with several cell targets. Cell. Signalling 14, 703-716.

(35) Kilcoyne, J., Keogh, A., Clancy, G., Le Blanc, P., Burton, I., Quilliam, M., Hess, P., and Miles, C. O. (2012) Improved isolation procedure for azaspiracids from shellfish, structural elucidation of azaspiracid-6, and stability studies. J. Agric. Food Chem. 60, 2447-2455.

(36) Twiner, M. J., El-Ladki, R., Kilcoyne, J., and Doucette, G. J. (2012) Comparative effects of the marine algal toxins azaspiracid-1, -2, and -3 on Jurkat $\mathrm{T}$ lymphocyte cells. Chem. Res. Toxicol. 25, 747-754.

(37) Morris, E. J., and Geller, H. M. (1996) Induction of neuronal apoptosis by camptothecin, an inhibitor of DNA topoisomerase-I: Evidence for cell cycle-independent toxicity. J. Cell Biol. 134, 757-770.

(38) Wall, M. E., Wani, M. C., Cook, C. E., Palmer, K. H., McPhail, A. T., and Sim, G. A. (1966) Plant antitumor agents. I. The isolation and structure of camptothecin, a novel alkaloidal leukemia and tumor inhibitor from Camptotheca acuminata. J. Am. Chem. Soc. 88, 38883890.

(39) Scheel-Toellner, D., Raza, K., Assi, L., Pilling, D., Ross, E., Lee, W., Curnow, S., Buckley, C., Akbar, A., Lord, J., and Salmon, M. (2008) Differential regulation of nuclear and mitochondrial Bcl-2 in T cell apoptosis. Apoptosis 13, 109-117.
(40) Pang, Y., Fang, C., Twiner, M. J., Miles, C. O., and Forsyth, C. J. (2011) Total synthesis and PPase inhibition of dinophysistoxin-2 and 2-epi-dinophysistoxin-2. Angew. Chem., Int. Ed. 50, 7631-7635.

(41) Perez-Gomez, A., Garcia-Rodriguez, A., James, K. J., FerreroGutierrez, A., Novelli, A., and Fernandez-Sanchez, M. T. (2004) The marine toxin dinophysistoxin-2 induces differential apoptotic death of rat cerebellar neurons and astrocytes. Toxicol. Sci. 80, 74-82.

(42) Vale, C., Nicolaou, K. C., Frederick, M. O., Vieytes, M. R., and Botana, L. M. (2010) Cell volume decrease as a link between azaspiracid-induced cytotoxicity and c-Jun- $\mathrm{N}$-terminal kinase activation in cultured neurons. Toxicol. Sci. 113, 158-168.

(43) Ito, E., Frederick, M. O., Koftis, T. V., Tang, W., Petrovic, G., Ling, T., and Nicolaou, K. C. (2006) Structure toxicity relationships of synthetic azaspiracid-1 and analogs in mice. Harmful Algae 5, 586591.

(44) Fan, T.-J., Han, L.-H., Cong, R.-S., and Liang, J. (2005) Caspase family proteases and apoptosis. Acta Biochim. Biophys. Sin. 37, 719727.

(45) Johnson, C., Jia, Y., Wang, C., Lue, Y.-H., Swerdloff, R. S., Zhang, X.-S., Hu, Z.-Y., Li, Y.-C., Liu, Y.-X., and Hikim, A. P. S. (2008) Role of caspase 2 in apoptotic signaling in primate and murine germ cells. Biol. Reprod. 79, 806-814.

(46) Bouchier-Hayes, L. (2010) The role of caspase-2 in stressinduced apoptosis. J. Cell. Mol. Med. 14, 1212-1224.

(47) Guo, Y., Srinivasula, S. M., Druilhe, A., Fernandes-Alnemri, T., and Alnemri, E. S. (2002) Caspase-2 induces apoptosis by releasing proapoptotic proteins from mitochondria. J. Biol. Chem. 277, 1343013437.

(48) Paroni, G., Henderson, C., Schneider, C., and Brancolini, C. (2001) Caspase-2-induced apoptosis is dependent on caspase-9, but its processing during UV- or tumor necrosis factor-dependent cell death requires caspase-3. J. Biol. Chem. 276, 21907-21915.

(49) Wang, J., Chun, H. J., Wong, W., Spencer, D. M., and Lenardo, M. J. (2001) Caspase-10 is an initiator caspase in death receptor signaling. Proc. Natl. Acad. Sci. U.S.A. 98, 13884-13888.

(50) Kuida, K., Haydar, T., Kuan, C.-Y., Gu, Y., Taya, C., Karasuyama, H., Su, M., Rakic, P., and Flavell, R. (1998) Reduced apoptosis and cytochrome c-mediated caspase activation in mice lacking caspase 9. Cell 94, 325-337.

(51) Li, P., Nijhawan, D., Budihardjo, I., Srinivasula, S., Ahmad, M., Alnemri, E., and Wang, X. (1997) Cytochrome $\mathrm{c}$ and dATP-dependent formation of Apaf 3/caspase 9 complex initiates an apoptotic protease cascade. Cell 91, 479-489.

(52) Kluck, R., Martin, S., Hoffman, B., Zhou, J., Green, D., and Newmeyer, D. (1997) Cytochrome c activation of CCP32-like proteolysis plays a critical role in a Xenopus cell-free apoptosis system. EMBO J. 16, 4639-4649.

(53) Walden, P. D., Globina, Y., and Nieder, A. (2004) Induction of anoikis by doxazosin in prostate cancer cells is associated with activation of caspase- 3 and a reduction of focal adhesion kinase. Urol. Res. 32, 261-265.

(54) Jehle, J., Schweizer, P., Katus, H., and Thomas, D. (2011) Novel roles for hERG $\mathrm{K}^{+}$channels in cell proliferation and apoptosis. Cell Death Dis. 2, e193.

(55) Waldhauser, K. M., Brecht, K., Hebeisen, S., Ha, H. R., Konrad, D., Bur, D., and Krähenbühl, S. (2008) Interaction with the hERG channel and cytotoxicity of amiodarone and amiodarone analogues. $\mathrm{Br}$. J. Pharmacol. 155, 585-595.

(56) Viluksela, M., Vainio, P. J., and Tuominen, R. K. (1996) Cytotoxicity of macrolide antibiotics in a cultured human liver cell line Matti Viluksela. J. Antimicrob. Chemother. 38, 465-473.

(57) Raffray, M., and Cohen, G. M. (1997) Apoptosis and Necrosis in Toxicology: A Continuum or Distinct Modes of Cell Death? Pharmac. Ther. 75, 153-177.

(58) Peter, M. E. (2011) Programmed cell death: Apoptosis meets necrosis. Nature 471, 310-312. 